Plaguicidas organoclorados y anticolinérgicos en ratones silvestres en ecosistemas de humedales costeros del Golfo de México

\title{
Organochlorine and anticholinergic pesticides in wild mice from wetland ecosystems of the Gulf of Mexico
}

\author{
Tammy Chi-Coyoc ${ }^{1 *}$, Griselda Escalona Segura ${ }^{1}$, Adriana Vallarino Moncada ${ }^{1}$, Jorge A. Vargas Contreras ${ }^{2}$, Guillermo E. \\ Castillo Vela ${ }^{1}$, Joel Lara Reyna ${ }^{3}$

\begin{abstract}
${ }^{1}$ El Colegio de la Frontera Sur. Unidad Campeche. Avenida Rancho Polígono 2-A, Ciudad Industrial, Lerma, 24500. San Francisco de Campeche, Campeche, México. E-mail: techi@ecosur.edu.mx (TCC), gescalon@ecosur.mx (GES), avallarinom@gmail.com (AVM), gcastillo@ecosur.mx (GECV).

${ }^{2}$ Facultad de Ciencias Químico Biológicas. Universidad Autónoma de Campeche. Av. Agustín Melgar S/N entre Calle 20 y Juan de la Barrera. Buenavista, 24039. San Francisco de Campeche, Campeche, México. E-mail: jalbino64@hotmail.com (JAVC).

${ }^{3}$ Colegio de Postgraduados. Campus Campeche. Carretera Haltunchen - Edzná, km 17.5, Sihochac. Champotón, Campeche, México. E-mail: jlara@colpos.mx (JLR).
\end{abstract} \\ * Corresponding author
}

Terminos Lagoon area is a highly important economic and biological area, and one of the most important fresh water reservoirs in Mesoamerica. This area has been affected by human activities such as the disposal of pollutants, including pesticides that cause damage among wildlife. Our research evaluated the exposition of three wild rodent species Oryzomys couesi, Peromyscus leucopus, and Reithrodontomys gracilis to organochlorine and anticholinergic pesticides in nine localities of Terminos Lagoon. We collected samples of brain, skeletal muscle, and liver to evaluate organochlorine and anticholinergic pesticides exposure. We measure acetylcholinesterase (AChE) activity as anticholinergic pesticide exposure sign. We found significant differences in acetylcholinesterase activity among localities in brain for two species $O$. couesi and $R$. gracilis, but not for skeletal muscle tissue. We found 20 organochlorine compounds in rodent's liver of which only lindane, aldrine and heptachlor were in amounts suggesting a recent exposure. The AChE inhibition is not enough evidence for anticholinergic pesticide exposure. Recent organochlorine pesticides application and exposition was detected, but sources are unknown, probably atmospheric deposition. Rodent exposure to pesticides could affect negatively its population dynamic. This detrimental effects can reach higher trophic levels because predators biomagnifies some of these compounds.

Key words: Aldrin; AChE inhibition; carbamates; DDT; organophosphorus; Pollution; wild rodents.

El área de Laguna de Términos es de gran importancia económica y biológica y es uno de los reservorios de agua dulce más importantes de Mesoamérica, la cual ha sido impactada por las actividades antrópicas que incorporan contaminantes, entre ellos los plaguicidas, los cuales dañan a la fauna silvestre. Este trabajo evaluó la exposición de tres especies de ratones silvestres Oryzomys couesi, Peromyscus leucopus y Reithrodontomys gracilis a plaguicidas anticolinérgicos y organoclorados en nueve sitios de Laguna de Términos. Se colectaron muestras de cerebro, músculo e hígado. Se midió la actividad de la enzima acetilcolinesterasa en músculo y cerebro como evidencia de la exposición a plaguicidas anticolinérgicos. Se determinaron lo compuestos organoclorados y sus concentraciones en muestras de hígado como evidencia de la exposición a los mismos. Se encontraron diferencias en la actividad de la enzima acetilcolinesterasa entre zonas de muestreo en cerebro para $O$. couesi y $R$. gracilis pero no en músculo. Se detectaron 20 compuestos organoclorados en el hígado de los ratones, de los cuales sólo el lindano, el aldrín y el heptacloro se encontraron en cantidades que sugieren una exposición reciente. La inhibición del a actividad de la AChE no es evidencia contundente para la exposición a plaguicidas anticolinérgicos en el área. Se detectó la aplicación y exposición reciente a plaguicidas OC, el pueden ser las deposiciones atmosféricas. La exposición de los ratones a los plaguicidas puede afectar negativamente su dinámica poblacional. Estos efectos perjudiciales pueden alcanzar niveles superiores en las redes tróficas ya que estos compuestos son persistentes y se biomagnifican a través de los niveles superiores de las redes tróficas.

(c) 2016 Asociación Mexicana de Mastozoología, www.mastozoologiamexicana.org 


\section{Introducción}

Los plaguicidas químicos sintéticos se han empleado desde la segunda mitad del siglo XX como primera opción para controlar insectos plaga y minimizar las pérdidas de las cosechas en todo el mundo. Su uso ha ido en aumento de manera descontrolada de casi 280 mil toneladas en 1964 solo para Estados Unidos hasta más de 2.3 millones de toneladas en 2007 a nivel mundial (EPA 2011). Como consecuencia del uso indiscriminado de plaguicidas, la salud humana y la ambiental se han visto afectadas por su interacción con la actividad biológica de los organismos benéficos para el ambiente (González-Castillo et al. 2012). Debido a que estos compuestos no son específicos, pueden causar efectos perjudiciales sobre el ecosistema y el ser humano (Bouchard et al. 2006) y amenazar el equilibrio ecológico (Hemingway y Ranson 2000).

Los compuestos organoclorados (OC) fueron los primeros en emplearse ampliamente en el control de insectos plaga por su alta efectividad en eliminarlos, particularmente el DDT (Snedeker 2001). Sin embargo, este compuesto fue prohibido al descubrir los efectos adversos de su uso tales como la alta capacidad carcinogénica y la alteración de la permeabilidad de la membrana neuronal, características comunes con otros OC. Además, al ser altamente lipofílicos, los OC se bioacumulan en los tejidos grasos y pueden biomagnificarse a través de las redes tróficas hacia los eslabones superiores, por lo cual se pueden detectar los compuestos o sus derivados dentro de los tejidos como evidencia de su exposición (Albert y Loera 2013). De igual manera, pueden producir a largo plazo disrupción endócrina, al imitar la acción de algunas hormonas como estrógenos y andrógenos debido a la similitud en su estructura química con una hormona endógena, llevando a cabo un efecto biológico similar (agonista) al de la hormona original o bloqueándolo (antagonista; Salame Méndez et al. 2008). Asimismo, estos compuestos son muy estables química y bioquímicamente, ya que su vida media en el ambiente es superior a los diez años y en muchos casos los productos de degradación parcial de estas sustancias son más estables que el compuesto original, como es el caso del DDT cuya vida media se estima en 10 años, mientras que sus productos de degradación, el DDE y DDD pueden durar en el ambiente por más de 30 años (Albert y Loera 2013).

Como una alternativa al uso de OC, se han empleado plaguicidas organofosforados (OP) y carbamatos, los cuales son más solubles en agua y poco solubles en lípidos, por lo que no se acumulan en los tejidos grasos y se degradan a una velocidad mayor en el ambiente (Lartiges y Garrigues 1995). Estos compuestos se consideran anticolinérgicos, es decir, impiden la hidrólisis del neurotransmisor acetilcolina (ACh) en colina y ácido acético por acción de la enzima acetilcolinesterasa (AChE), por lo cual la ACh se acumula en las terminaciones del sistema nervioso central y periférico (Albert y Loera 2013). De esta manera, se alteran funciones como la termorregulación y el comportamiento (actividad, tiempo de forrajeo, habilidad de aprendizaje y el consumo de agua o alimento), lo cual conlleva a pérdida de peso, problemas en el desarrollo, y bajo éxito reproductivo en aves y mamíferos (Story y Cox 2001).

Las respuestas biológicas de los vertebrados ante los plaguicidas pueden permanecer por semanas después de que los compuestos se han degradado en el ambiente, por lo que estas respuestas pueden servir como indicadores de su exposición, también llamados biomarcadores de exposición. Los biomarcadores de exposición se definen como respuestas biológicas que permiten detectar y medir una sustancia exógena o sus metabolitos, o el producto de una interacción entre el agente xenobiótico y algunas moléculas o células blanco dentro de un organismo (van der Oost et al. 2003). Esto permite confirmar y evaluar la exposición de individuos a una sustancia o grupo de sustancias en particular, relacionando la exposición externa y la dosimetría interna (van der Oost et al. 2003). La actividad de la enzima AChE es uno de los biomarcadores de exposición más usados para evaluar la exposición a plaguicidas anticolinérgicos por ser fácil de medir en laboratorio y poco costoso en comparación con otros métodos (Walker et al. 2012).

Con el propósito de estimar el impacto de los plaguicidas sobre la fauna silvestre, numerosos estudios han evaluado, bajo condiciones controladas, su efecto sobre animales en laboratorio como peces (Fulton y Key 2001), roedores (Astroff y Young 1998; Timofeeva et al. 2008; Roegge et 
al. 2008) y aves (Fildes et al. 2009), tomando en cuenta el papel de las características inherentes a los organismos como la especie, el sexo y la edad.

Como consecuencia, los efectos sobre la fauna silvestre aún no son comprendidos del todo, ya que existen factores ambientales que juegan roles fundamentales en la cinética de degradación y persistencia de los plaguicidas, que influyen en la exposición de los organismos a los plaguicidas (Albert y Loera 2013). De igual forma, la manera en la cual los organismos responden a dichos factores y las interacciones con otros organismos, son importantes para elucidar el efecto ecológico de los plaguicidas. Algunas respuestas conductuales asociadas a interacciones interespecíficas como la depredación pueden verse alteradas por la exposición a plaguicidas e impactar a nivel poblacional disminuyendo el número de individuos. Esto debido a que los animales pueden ser más susceptibles a ser capturados o, en el caso de los depredadores, pueden no ser lo suficientemente hábiles para cazar a sus presas. Por otra parte, pueden bioacumular y biomagnificar los plaguicidas, y producir a largo plazo la disminución en el éxito reproductivo (Fernie y Letcher 2010; Bourgeon et al. 2013).

Debido a que los plaguicidas son transportados largas distancias dependiendo de su persistencia, pueden afectar a organismos que estén alejados de la zona de influencia (como es el caso del DDT aplicado en zonas tropicales y que se ha detectado como DDE en el ártico viajando miles de kilómetros). Además, pueden sufrir transformaciones dependiendo de las características del medio a través del cual son transportados (aire, agua, suelo), la manera en que se aplican y la presencia de cuerpos de agua o de precipitación (Castro y Yoshida 1971, Ghadiri et al. 1995). Tal es el caso de la temperatura y la salinidad en ambientes acuáticos, mientras que en ambientes terrestres, son de gran importancia la estructura y la química del suelo (Poissant et al. 2008). Asimismo, las características químicas propias del plaguicida y la vida media están relacionadas con su persistencia en el ambiente, mientras que el tiempo desde la aplicación y la distancia influyen en los productos de degradación detectados en un sitio determinado (Karpuzcu et al. 2013; Mackay et al. 2014).

Como parte la fauna no dañina que se ve afectada por los plaguicidas se encuentran aquellas especies que habitan en los humedales. Estos ecosistemas son de gran importancia por ser zonas de transición entre los ambientes terrestres y marinos. Fungen como zonas de refugio y crianza para muchas especies, además de ser reservorio de nutrientes y metales que escurren de los ambientes circundantes, y que en cantidades excesivas pueden fungir como contaminantes, a lo cual se suma la descarga de plaguicidas y otros compuestos procedentes de los asentamientos humanos cercanos (Mitsch y Gosselink 2000).

Entre los organismos que se encuentran en contacto directo con los plaguicidas adsorbidos en el suelo están los mamíferos herbívoros, tal es el caso de los roedores debido a sus hábitos de forrajeo, removiendo el suelo para encontrar u ocultar semillas y depredar raíces y plántulas. Los roedores son importantes ya que fungen como sostén de muchos depredadores, conectando el nivel de los productores primarios con los consumidores secundarios o depredadores en los ecosistemas terrestres (Chamucero-Santacoloma et al. 2011).

Los humedales del Área de Protección de Floray Fauna Laguna deTérminos (APFFLT) en Campeche en conjunto con la Reserva de la Biósfera Pantanos de Centla en Tabasco, forman la unidad ecológica costera más importante de Mesoamérica por su productividad natural y biodiversidad (CONAGUA 2007). Históricamente, la Laguna de Términos ha sido una zona fuertemente impactada por el humano debido al crecimiento poblacional y a las actividades productivas como la agricultura, ganadería y la industria petrolera (Villalobos 2015). A pesar de que los OC como el DDT dejaron de usarse en México oficialmente desde el año 2000 para el control de vectores de enfermedades como el paludismo y dengue (SSA 2001), en el área de Laguna de Términos se ha reportado la presencia de compuestos de las familias del diclorodifeniltricloroetano (DDT), endosulfanes, drines, clordanos, isómeros del hexaclorociclohexano $(\mathrm{HCHs})$ y el OP Clorpirifos, tanto en sedimento como en biota acuática, (Carvalho et al. 2009; Ramírez-Elías et al. 2016) y se ha dejado de lado el conocimiento sobre el impacto de estos compuestos en los organismos terrestres. 
Por lo anterior, el presente trabajo tiene como objetivo identificar si existe una exposición reciente a plaguicidas $\mathrm{OC}$ y anticolinérgicos en tres especies de ratones (Oryzomys couesi, Peromyscus leucopus y Reithrodontomys gracilis), esto, a través de determinar y cuantificar los plaguicidas OC acumulados en el hígado, y de caracterizar y comparar la actividad de la enzima acetilcolinesterasa (AChE) en músculo esquelético y cerebro como efecto de la exposición a plaguicidas anticolinérgicos (OP y carbamatos) en diferentes zonas del APFFLT.

\section{Materiales y métodos}

Área de estudio. El APFFLT se localiza al suroeste de México, en la costa del estado de Campeche y comprende parte de los municipios de Carmen, Palizada y Champotón. Es parte del complejo ecológico de la planicie costera que controla los procesos deltaicos del sistema de ríos GrijalvaUsumacinta, que es el de mayor volumen de descarga de agua dulce y sedimentos terrígenos hacia el mar en todo el país. El clima es tropical húmedo y la precipitación anual va de 1,100 a 2,000 mm. Se presentan tres temporadas, Iluvias (junio a septiembre), secas (febrero a mayo) y nortes (octubre a enero; CONAGUA 2007).

El trabajo de campo se llevó a cabo de febrero a agosto de 2015 en nueve sitios del APFFLT: Rancho Nohan, Rancho R1 y Tixchel, Aguacatal, Las Bodegas, La Toza, Los Corralitos, San Román, La Leona/Nicte-Ha (Figura 1).

Captura de roedores. En cada sitio de muestreo la captura se realizó con 100 trampas Sherman cebadas con una mezcla de avena-semillas de girasol-vainilla dispuestas cada una a $10 \mathrm{~m}$ dentro de una cuadricula de $100 \times 100$ m (Jones y Teeling 2006). Se eligieron individuos adultos de Oryzomys couesi, Peromyscus leucopus y Reithrodontomys gracilis por ser abundantes en el área y

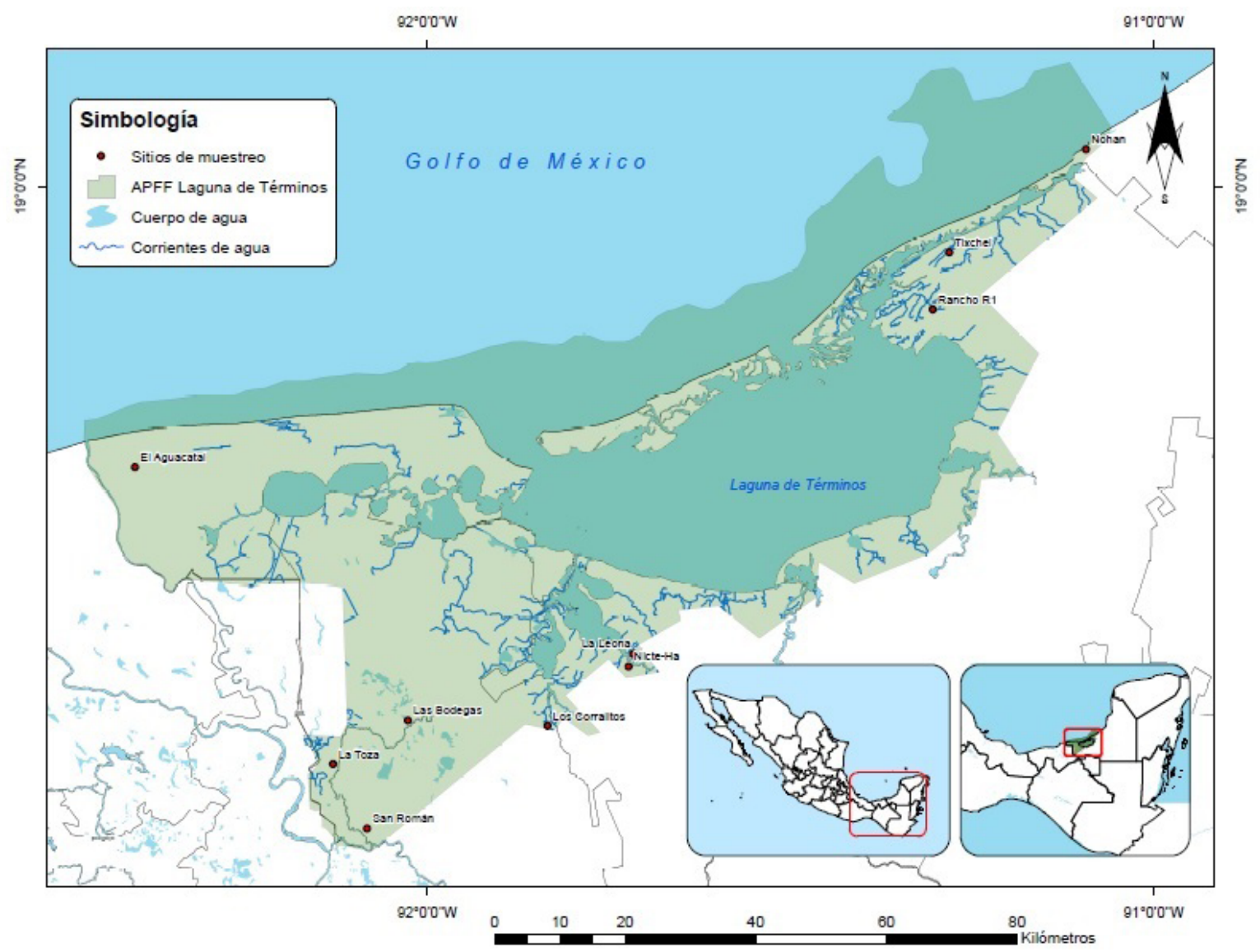

Figura 1. Distribución de los sitios de muestreo en El Área de Protección de Flora y Fauna Laguna de Términos en Campeche. Los sitios muestreados fueron Rancho Nohan, Tixchel, Rancho R1, El Aguacatal, La Leona/Nicté-Ha, Los Corralitos, Las Bodegas, San Román y La Toza. 
debido a que no se encuentran bajo algún estado de protección (SEMARNAT 2010; IUCN 2015). Se identificaron hasta especie con el apoyo de guías de campo (Reid 2009; Álvarez-Castañeda et al. 2015) y se tomaron las medidas morfométricas convencionales (longitud total, longitud de la cola, longitud de la pata trasera, longitud de la hendidura de la oreja, masa, sexo y edad). Estos organismos se sacrificaron siguiendo el método de eutanasia por dislocación cervical (SAGARPA 2014) para tomar muestras de cerebro, de músculo esquelético e hígado, los cuales fueron congelados a una temperatura de -20 a $-4{ }^{\circ} \mathrm{C}$ hasta el momento de su análisis en laboratorio.

Trabajo de Laboratorio. La determinación de la actividad de la enzima AChE en cerebro y músculo esquelético se hizo siguiendo el método de Ellman et al. (1961), adaptado a un microensayo (Campoy et al. 1992). La proteína se determinó con el método de Bradford (1976). A partir de los valores de proteínas se procedió a estimar la actividad de la acetilcolinesterasa (AChE) mediante el método de Ellman et al. (1961).

Para la determinación de los compuestos OC, las muestras de hígado se homogenizaron y secaron con sulfato de sodio, la extracción se realizó mediante el método Soxhleth en cloruro de metileno:hexano (1:1; EPA 1996). Se empleó un cromatógrafo de gases Varian 3800 con un detector de captura de electrones con fuente de ${ }^{63} \mathrm{Ni}$, con columna cromatográfica capilar HT8 (60 m x $0.25 \mathrm{~mm} ; 25 \mu \mathrm{m}$ film thickness) (SGE Analytical Science, USA). El cálculo de las áreas de los picos se realizó con el programa Star Chromatography Workstation versión 6 . La identificación y cuantificación de los plaguicidas $\mathrm{OC}$ se realizó con un estándar cuya mezcla de compuestos (SUPELCO 47426-U CLP Organochlorine Pesticide Mix) fueron: alfa, beta, gamma y delta-HCH, heptacloro, epóxido de heptacloro, a-endosulfán, $\beta$-endosulfán, endosulfán sulfato, dieldrín, aldrín, endrín, endrín aldehido, p,p'-DDD, p,p'-DDE y p,p'-DDT.

Todos los análisis de laboratorio se realizaron bajo la supervisión del Jaime Rendón von Osten en el Laboratorio de Ecotoxicología del Instituto de Ecología, Pesquerías y Oceanografía del Golfo de México (EPOMEX) de la Universidad Autónoma de Campeche.

Análisis de datos. Los análisis estadísticos se realizaron con el programa InfoStat/S Versión 2016e. Se analizaron 20 individuos de $R$. gracilis (seis hembras y 14 machos); 23 O. couesi (cuatro hembras y 18 machos) y 14 P. leucopus (seis hembras y ocho machos). El área de estudio se dividió en dos zonas para el análisis de la actividad de la enzima AChE: la zona de ríos que incluye los sitios La Leona/Nicte-Ha, Los Corralitos, Las Bodegas, La Toza y San Román; y la zona de costa que incluye los sitios Nohan, Tixchel, Rancho R1 y El Aguacatal. Se realizaron análisis de U de Mann-Whitney para comparar la actividad de la AChE en músculo esquelético, en cerebro y entre sexos, entre zonas en $O$. couesi y $R$. gracilis. La actividad de esta enzima para $P$. leucopus sólo se reportó debido a que se encontró únicamente en la zona de costa (Quinn y Keough 2007).

Las concentraciones de plaguicidas determinados en las muestras de hígado se compararon entre especies y sitios mediante análisis de ANOVA mixto (Quinn y Keough 2007). Los resultados de los plaguicidas se agruparon en familias con el mismo peso molecular o de acuerdo a sus productos de degradación como se muestra a continuación:

$$
\begin{aligned}
& \Sigma \mathrm{DDT}=\mathrm{p}, \mathrm{p}^{\prime}-\mathrm{DDT}+\mathrm{p}, \mathrm{p}^{\prime}-\mathrm{DDD}+\mathrm{p}, \mathrm{p} \text {-DDE } \\
& \Sigma \text { Endosulfanes }=\mathrm{a}-\mathrm{Endosulfán}+\beta \text {-Endosulfán }+ \text { Endosulfán Sulfato } \\
& \Sigma \mathrm{HCH}=\mathrm{a}-\mathrm{HCH}+\beta-\mathrm{HCH}+\gamma-\mathrm{HCH} \text { (lindano })+\delta-\mathrm{HCH} \\
& \Sigma \text { Aldrines }=\text { Aldrín }+ \text { Dieldrín } \\
& \Sigma \text { Endrines }=\text { Endrín }+ \text { Endrín aldehído }+ \text { Endrín cetona } \\
& \Sigma \text { Heptacloros }=\text { Heptacloro }+ \text { Epóxido de Heptacloro } \\
& \Sigma \text { Clordanos = trans-Clordano }+ \text { cis-Clordano } \\
& \text { Metoxicloro }
\end{aligned}
$$

Además, se determinó la temporalidad de la exposición a los plaguicidas mediante el cálculo de la proporción que ocupan los productos de degradación e isómeros presentes en los plaguicidas de grado técnico, con respecto al total de las concentraciones de cada tipo de plaguicida, expresadas 
como sumatorias $(\Sigma)$. Así, si la proporción de los productos de degradación e isómeros en el hígado corresponde a la proporción que contienen los plaguicidas de grado técnico con respecto a la sumatoria del plaguicida $(\Sigma)$, se consideró un indicio de que la exposición a alguno de los compuestos encontrados ha ocurrido en un tiempo menor a la vida media del compuesto, por lo tanto es reciente.

\section{Resultados}

Actividad de la enzima AChE. No se encontraron diferencias significativas en la comparación entre sexos para ninguna de las tres especies. Para $O$. couesi no se encontraron diferencias significativas en la actividad de la AChe en músculo esquelético entre zonas $(U=71, p=0.84)$. Sin embargo, se encontraron diferencias significativas en la actividad de la AChE en cerebro entre zonas $(U=63, p$ $=0.03$; Tabla 1, Figura 2).

De manera similar, para $R$. gracilis no se encontraron diferencias significativas en la actividad de la AChE en músculo esquelético entre zonas $(U=83, p=0.45)$, mientras que en la actividad de la AChE en cerebro sí se encontraron diferencias significativas $(U=47, p=0.03)$. En tanto $P$. leucopus se registró una actividad promedio de AChE en cerebro de $26.35 \pm 5.87 \mathrm{ng} \mathrm{nmoles} / \mathrm{min} / \mathrm{mL}$, y en músculo fue $5.52 \pm 1.52 \mathrm{ng} \mathrm{nmoles} / \mathrm{min} / \mathrm{mL}$ (Tabla 3 ).

Plaguicidas $O C$ en ratones. Se detectaron 20 compuestos $O C$ entre los que se encuentran las familias de DDT, drines, clordanos, heptacloros, metoxicloro, isómeros de HCH y endosulfán (Tabla 4). En las concentraciones de las sumas de plaguicidas en hígado de ratón se encontró que las concentraciones varían por sitio para las sumas de cada familia de compuestos $\mathrm{OC}$, pero la especie y la interacción entre la especie y el sitio no influyeron de manera significativa en esta variación (Tabla 5).

Los OC $\Sigma$ DDTs, $\Sigma$ HCHs y $\Sigma$ Endrín fueron los de mayor concentración en los ratones del área de estudio con promedios de $876.6 \mathrm{ng} \cdot \mathrm{g}^{-1}, 546.1 \mathrm{ng} \cdot \mathrm{g}^{-1}$ y $451.9 \mathrm{ng} \cdot \mathrm{g}^{-1}$ respectivamente. Los sitios con más OC fueron La Leona/Nicte-Ha, Rancho Nohan y San Román con más de quince compuestos. Por otra parte en Aguacatal se encontraron cuatro compuestos: heptacloro, metoxicloro, $\mathrm{a}-\mathrm{HCH}$ y $\beta-\mathrm{HCH}$, en Lo Corralitos se detectaron tres compuestos: heptacloro, metoxicloro y a-HCH, en La Toza se encontraron dos compuestos: endosulfán sulfato y $\beta-\mathrm{HCH}$, mientras que en el sitio Las Bodegas no se detectaron plaguicidas (Tabla 4).

Los integrantes de la familia del DDT estuvieron presentes en cinco sitios de los nueve muestreados siendo más abundantes en los sitios La Leona/Nicte-Ha, San Román y Tixchel en donde se observaron proporciones de DDT/LDDT > 0.75, en comparación con las proporciones

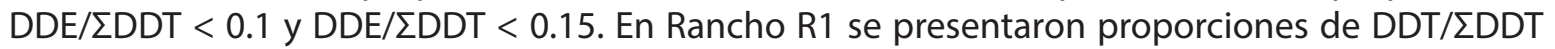
$=0.32, \mathrm{DDE} / \Sigma \mathrm{DDT}=0.43$ y DDE/ $\mathrm{DDT}=0.24$, mientras en Tixchel las proporciones fueron DDT/ $\Sigma \mathrm{DDT}=0.96$ y DDE/ $\Sigma \mathrm{DDT}=0.03$ (Tabla 4 ).

La familia de los endosulfanes estuvo presente en seis sitios. En La Leona/Nicte-Ha se observaron la proporciones a-Endosulfán $/ \Sigma$ Endosulfanes $=0.26, \beta$-Endosulfán $/ \Sigma$ Endosulfanes $=$ 0.54 , en San Román se encontró $a$-Endosulfán $/ \Sigma$ Endosulfanes $=0.11 \beta$-Endosulfán $/ \Sigma$ Endosulfanes $=0.72$ y Sulfato de Endosulfán $/ \Sigma$ Endosulfanes $=0.16$ y en la Toza se detectó únicamente el sulfato de endosulfán. Por otra parte, en Tixchel sólo se encontró $\beta$-Endosulfán, en tanto que en R1 sólo se detectó el sulfato de endosulfán, y en Tixchel se detectó el $\beta$-Endosulfán (Tabla 4, Figura 5).

Tabla 1. Resultado de la prueba U de Mann Whitney en la comparación de la actividad de la enzima AChE en músculo esquelético y cerebro de Oryzomys couesi entre zonas.

\begin{tabular}{|c|c|c|c|c|}
\hline Tejido & Zona & Estadístico H & Gl & $\mathbf{P}$ \\
\hline Músculo esquelético & Ríos vs Costa & 71 & $\mathrm{n} 1=8, \mathrm{n} 2=15$ & 0.84 \\
\hline Cerebro & Ríos vs Costa & 63 & $\mathrm{n} 1=8, \mathrm{n} 2=15$ & 0.03 \\
\hline
\end{tabular}


a)

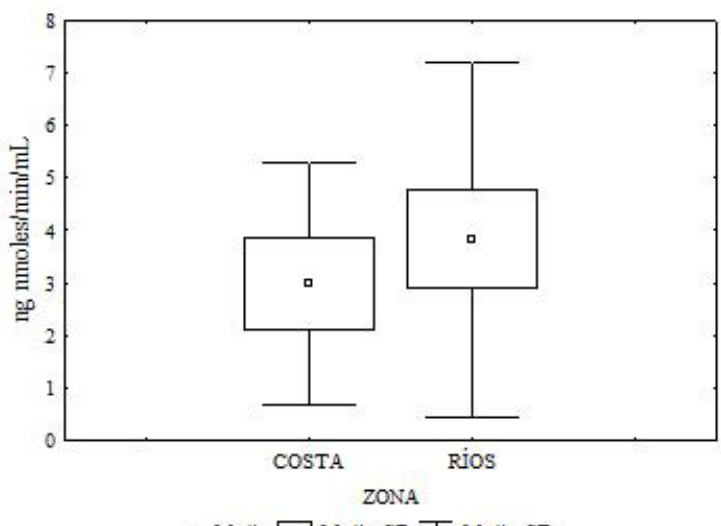

b)

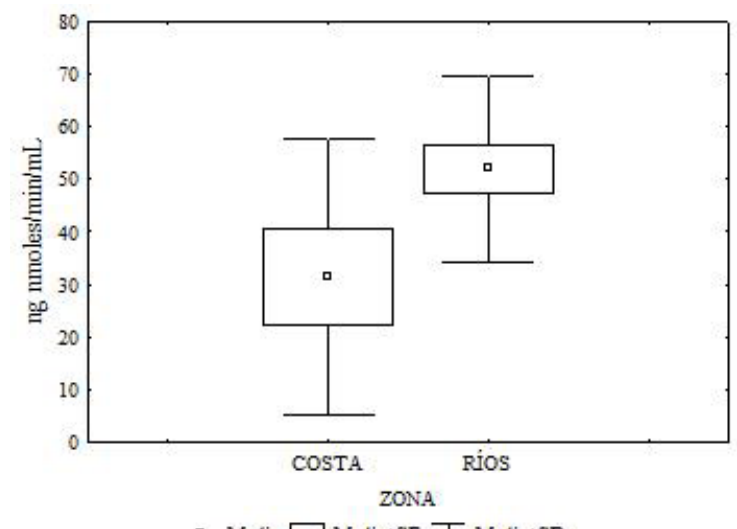

Figura 2. Actividad de la AChE en músculo (a) y cerebro (b) en Oryzomys. couesi por zona.

Los $\mathrm{HCH}$ se encontraron en todos los sitios. Se observaron proporciones de $\mathrm{a}-\mathrm{HCH} / \Sigma \mathrm{HCH}=$ $0.06, \beta-\mathrm{HCH} / \Sigma \mathrm{HCH}=0.22, \gamma \mathrm{HCH} / \Sigma \mathrm{HCH}=0.18$ y $\delta \mathrm{HCH} / \Sigma \mathrm{HCH}=0.31$ en La Leona/Nicte-Ha. En San Román se observaron proporciones de $\mathrm{a}-\mathrm{HCH} / \Sigma \mathrm{HCH}=0.14, \beta-\mathrm{HCH} / \Sigma \mathrm{HCH}=0.25, \gamma \mathrm{HCH} / \Sigma \mathrm{HCH}=$ 0.25 y $\delta \mathrm{HCH} / \Sigma \mathrm{HCH}=0.33$. En Corralitos se detectó sólo $a-\mathrm{HCH}$ y en La Toza $\beta-\mathrm{HCH}$. En Rancho R1 predominó el lindano con proporción $\gamma \mathrm{HCH} / \Sigma \mathrm{HCH}=0.44$, en Rancho Nohan predomina el $\beta-\mathrm{HCH}$ $/ \Sigma \mathrm{HCH}=0.72$, en Tixchel las proporciones fueron $\delta \mathrm{HCH} / \Sigma \mathrm{HCH}=0.46$ y $\mathrm{\gamma HCH} / \Sigma \mathrm{HCH}=0.38$, y en Aguacatal se encontraron proporciones de $a-H C H / \Sigma H C H=0.66$ y $\beta-H C H / \Sigma H C H=033$ (Tabla 4, Figura 5).

Los drines estuvieron en las siguientes proporciones: Aldrín/ $\Sigma$ Aldrín $=0.25$, Dieldrín/ $\Sigma$ Aldrín $=0.69$ en La Leona/Nicte-Ha, En Rancho R1 y Tixchel sólo se encontró aldrín, En Rancho R1 y San Román sólo se encontró endrín cetona, y sólo en Rancho Nohan se detectó endrín en proporción de Endrín/ $/$ Endrín = 0.3 (Tabla 4, Figura 5).

Los heptacloros se encontraron en ocho de los nueve sitios con proporciones de Heptacloro/ $\Sigma$ Heptacloro $>0.8$ y Epóxido de heptacloro/ $\Sigma$ Heptacloro $<0.2$ (Tabla 4).

Los clordanos se encontraron cuatro de los nueve los sitios. En La Leona/Nicte-Ha se observaron proporciones de trans-Clordano $/ \Sigma$ Clordanos $=0.57$ y cis-Clordano $/ \Sigma$ Clordanos $=0.42$, en San Román las proporciones fueron trans-Clordano $/ \Sigma$ Clordanos $=0.27$ y cis-Clordano $/ \Sigma$ Clordanos $=$ 0.72 , y en Rancho Nohan se observaron proporciones de trans-Clordano/ $\Sigma$ Clordanos $=0.3$ y cisClordano $/ \Sigma$ Clordanos $=0.69$ (Tabla 4, Figura 5).
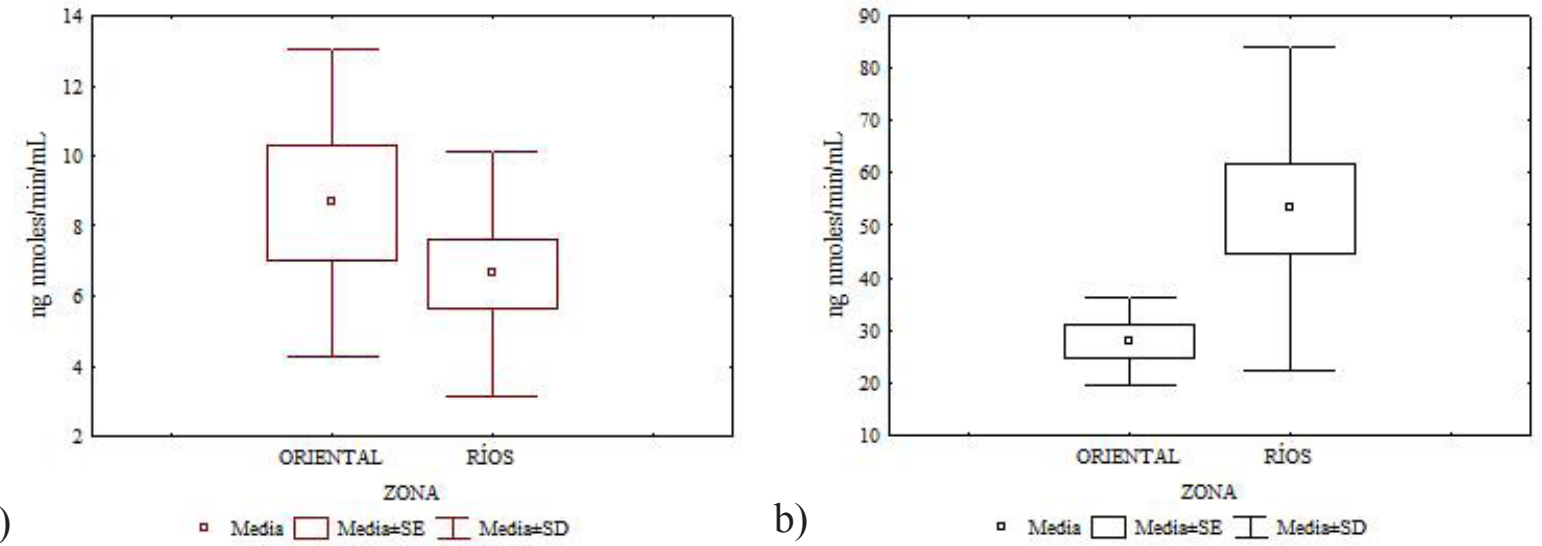

Figura 3. Actividad de la AChE en músculo (a) y cerebro (b) en Reithrodontomys gracilis por zona. 
Tabla 2. Resultado de la prueba $U$ de Mann Whitney en la comparación de la actividad de la enzima AChE en músculo esquelético y cerebro de Reithrodontomys gracilis entre zonas.

\begin{tabular}{|c|c|c|c|c|}
\hline Tejido & Zona & Estadístico $\mathbf{H}$ & Gl & $\mathbf{P}$ \\
\hline Músculo esquelético & Ríos vs Costa & 83 & $\mathrm{n} 1=7, \mathrm{n} 2=13$ & 0.45 \\
\hline Cerebro & Ríos vs Costa & 47 & $\mathrm{n} 1=7, \mathrm{n} 2=13$ & 0.03 \\
\hline
\end{tabular}

\section{Discusión y conclusiones}

Inhibición de la AChE. La actividad de las colinesterasas es uno de los procesos metabólicos más susceptibles de ser alterados, de manera inmediata, en presencia de plaguicidas OP y carbámicos. Es por ello que su cuantificación se emplea como un instrumento para determinar la exposición a dichos compuestos, aún después de que éstos se han degradado en el ambiente (Depledge y Fossi 1994). Sin embargo, se ha reportado que esta enzima se puede inhibir ante la presencia de grandes cantidades de metales pesados como $\mathrm{Cd}^{2+}, \mathrm{Hg}^{2+}, \mathrm{Pb}^{2+}$ así como sulfato de cobre y cloruro de cadmio, y productos de la combustión de hidrocarburos (Payne et al. 1996).

Para el área de Laguna de Términos se encontró evidencia de la disminución en la actividad de la enzima AChE en cerebro en $O$. couesi y $R$. gracilis únicamente en cerebro, en donde la menor actividad se observó en la zona de costa a pesar de que en la zona de ríos hay una fuerte actividad agrícola y uso de plaguicidas OP, particularmente por las plantaciones arroceras en las que se emplean compuestos como clorpirifos etil, monocrotofos y malatión contra insectos plaga como la chinche café (Oevalus insularis), el gusano soldado (Spodoptera frugiperda) y otros gusanos defoliadores o cortadores como el gusano cabezón (Telicota sp.) y el gusano medidor (Trichoplusia sp.; Orona-Castro 2008). También es empleado paratión para combatir otras plagas como la mosca de la fruta (Anastrepha sp.), trips (Selenothrips rubocinctus) y escamas (Coccus mangiferae), así como el carbamato carbofurán para el control de barrenadores (Xiloborus sp., Apate sp. y Batocera sp.) (Tucuch Cauich et al. 2005, Reyes-Montero 2014).

En la zona de costa hay poca actividad agrícola entre la que destaca el cultivo de chile (Capsium annuum) en donde se emplean los OP malatión y metamidofos para el control de plagas (Botello et al. 1998). No obstante, la actividad preponderante es la extracción de hidrocarburos, la cual podría estar exponiendo a los ratones a metales pesados y a productos de combustión de hidrocarburos, los cuales en grandes cantidades pueden estar influyendo en la inhibición de la AChE (Payne et al. 1996).

Además, la inhibición diferencial de la AChE en cerebro y músculo puede deberse a la presencia de la enzima BChE predominantemente en el músculo esquelético, la cual ha demostrado tener un efecto protector frente a la intoxicación por OP en roedores como ratas y cobayas, así como en primates al hidrolizar a la acetilcolina auxiliando en la transmisión del impulso nervioso (Raveh et al. 1997; Allon et al. 1998; Mehrani 2004).

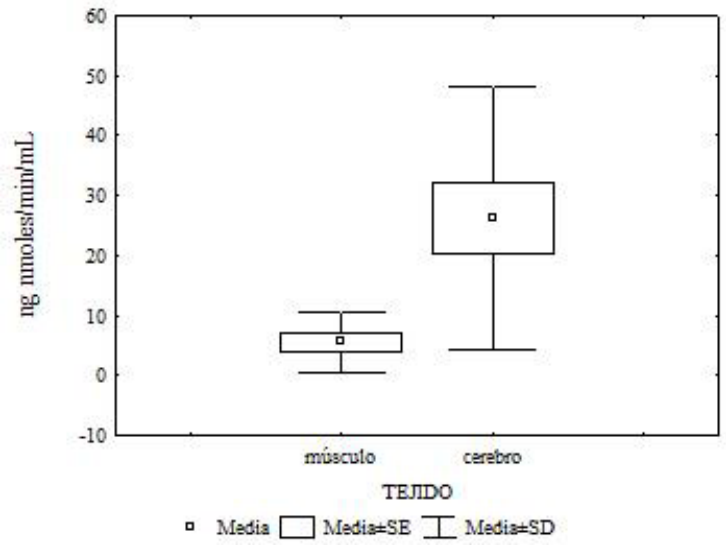

Figura 4. Actividad de la AChE en músculo (a) y cerebro (b) en Peromyscus. leucopus en la zona de costa. 
Tabla 3. Actividad enzimática en músculo esquelético y cerebro de las tres especies de roedores evaluados.

\begin{tabular}{lllrl}
\hline Especie & Zona & Tejido & Media & SE \\
\hline O. conesi & Costa & Músculo e. & 3 & 0.94 \\
& & Cerebro & 31.46 & 9.24 \\
& Ríos & Músculo e. & 3.83 & 0.87 \\
& & Cerebro & 52.09 & 4.56 \\
R. gracilis & Costa & Músculo e. & 8.68 & 0.97 \\
& & Cerebro & 27.9 & 3.22 \\
& Ríos & Músculo e. & 6.64 & 1.66 \\
& & Cerebro & 53.72 & 8.57 \\
& & Músculo e. & 5.52 & 1.52 \\
& Costa & Cerebro & 26.35 & 5.87 \\
\hline
\end{tabular}

Para el género Peromyscus se cuenta con valores de referencia de otras especies como $P$. manuculatus, cuya actividad de AChE cerebral en condiciones de laboratorio fue de $7.931 \mu \mathrm{mol} /$ AThCh hidrolizada/min/g de cerebro en machos y de $7.731 \mu \mathrm{mol} /$ AThCh hidrolizada/min/g en hembras (Block et al. 1993), mientras que la actividad de la misma especie en ejemplares silvestres fue cercano a $9.2 \mu \mathrm{mol} / \mathrm{AThC}$ hidrolizada/min/g de cerebro (Block et al. 1999). Además, Block et al. (1993) reporta que, en vida silvestre, la actividad de la AChE en P. maniculatus y P. leucopus no son estadísticamente diferentes.

De igual manera, Andrade-Herrera (2011) reportó valores de actividad promedio de AChE en músculo de $5.134 \mathrm{nmoles} / \mathrm{min} / \mathrm{mL}$ en $P$. difficilis y de $6.579 \mathrm{nmoles} / \mathrm{min} / \mathrm{mL}$ en $P$. melanotis. En este trabajo $P$. leucopus tuvo una actividad promedio máxima en músculo de $16.26 \mathrm{ng} \mathrm{nmoles} / \mathrm{min} /$ $\mathrm{mL}$ de proteína, mientras que en cerebro fue de $65.90 \mathrm{ng} \mathrm{nmoles} / \mathrm{min} / \mathrm{mL}$ de proteína, valores por encima de lo reportado para otras especies del mismo género.

Sin embargo, se debe tomar en cuenta que los organismos de diferentes especies e incluso de la misma, pueden tener variaciones en sus respuestas a los estímulos ambientales como consecuencia de las adaptaciones regionales, e incluso, especies provenientes de los mismos sitios de colecta pueden presentar respuestas diferenciales entre las condiciones de laboratorio y en vida silvestre (Dell'Omo et al. 2003). Las colinesterasas pueden verse afectadas por factores naturales

Tabla 5. Resultados del ANOVA mixto para contrastar el efecto de los factores sitio y especie sobre la sumas de los plaguicidas organoclorados, en donde sólo se muestran los resultados del factor sitio por tener un efecto significativo en la variabilidad de todos los plaguicidas. Un asterisco $(*)$ indica una $P<0.05$, dos asteriscos $\left(^{* *}\right)$ indican un $P<0.001$,

\begin{tabular}{lllrlrrrr}
\hline Plaguicida & Variable & Efecto & Gl Efecto & MS Efecto & Gl Error & MS Error & F & p \\
\hline$\Sigma$ DDT & Sitio & Fijo & 7 & 1961640 & 42 & 249476.30 & 7.86 & $* *$ \\
$\Sigma$ Endosulfan & Sitio & Fijo & 7 & 569276.2 & 42 & 40309.59 & 14.12 & $* *$ \\
$\Sigma$ HCH & Sitio & Fijo & 7 & 1301731 & 42 & 80065.07 & 16.25 & $* *$ \\
$\Sigma$ Drines & Sitio & Fijo & 7 & 78822.65 & 42 & 11285.51 & 6.98 & $* *$ \\
$\Sigma$ Endrin & Sitio & Fijo & 7 & 244085.7 & 42 & 99324.44 & 2.46 & $*$ \\
$\Sigma$ Heptacloro & Sitio & Fijo & 7 & 290284.0 & 42 & 18248.46 & 15.91 & $* *$ \\
$\Sigma$ Clordano & Sitio & Fijo & 7 & 77801.79 & 42 & 11106.83 & 7.01 & $* *$ \\
$\Sigma$ Metoxicloro & Sitio & Fijo & 7 & 2977363 & 42 & 182558.1 & 16.31 & $* *$ \\
\hline
\end{tabular}


Tabla 4. Concentración de plaguicidas organoclorados (ng.g- ${ }^{-1}$ peso seco) en hígado por especie y sitio.

\begin{tabular}{|c|c|c|c|c|c|c|c|c|c|c|c|c|c|}
\hline \multirow[b]{2}{*}{ Plaguicida /Sitio } & \multicolumn{7}{|c|}{ Oryzomys couesi } & \multicolumn{2}{|c|}{$\begin{array}{c}\text { Peromyscus } \\
\text { leucopus }\end{array}$} & \multicolumn{4}{|c|}{ Reithrodontomys gracilis } \\
\hline & AG & $\mathbf{R} 1$ & RNH & TIX & COR & $\begin{array}{l}\text { NTH/ } \\
\text { LEO }\end{array}$ & SR & RNH & TIX & $\mathbf{R} 1$ & BDG & SR & TOZA \\
\hline pp' DDD & $<4.62$ & $<4.62$ & $<4.62$ & 30.9 & $<4.62$ & 781.1 & 107.8 & 82.1 & $<4.62$ & $<4.62$ & $<4.62$ & $<4.62$ & $<4.62$ \\
\hline pp'DDE & $<4.62$ & $<4.62$ & $<4.62$ & $<4.62$ & $<4.62$ & 400.7 & 13.4 & 72.5 & $<4.62$ & $<4.62$ & $<4.62$ & $<4.62$ & $<4.62$ \\
\hline pp'DDT & $<4.62$ & $<4.62$ & 54.1 & 974.4 & $<4.62$ & 4234.8 & 64.2 & $<4.62$ & $<4.62$ & $<4.62$ & $<4.62$ & 2293.3 & $<4.62$ \\
\hline$\Sigma \mathrm{DDT}$ & $<4.62$ & $<4.62$ & 54.1 & 1005.3 & $<4.62$ & 5416.7 & 185.3 & 154.6 & $<4.62$ & $<4.62$ & $<4.62$ & 2293.3 & $<4.62$ \\
\hline$\alpha$-Endosulfan & $<4.62$ & $<4.62$ & 61.7 & $<4.62$ & $<4.62$ & 831.8 & 22.0 & 102.5 & $<4.62$ & $<4.62$ & $<4.62$ & $<4.62$ & $<4.62$ \\
\hline$\beta$-Endosulfan & $<4.62$ & $<4.62$ & 14.7 & 15.8 & $<4.62$ & 2067.7 & 139.0 & 162.7 & $<4.62$ & $<4.62$ & $<4.62$ & $<4.62$ & $<4.62$ \\
\hline Endosulfan Sulfato & $<4.62$ & 4.1 & $<4.62$ & $<4.62$ & $<4.62$ & $<4.62$ & 93.7 & 31.5 & $<4.62$ & $<4.62$ & $<4.62$ & $<4.62$ & 15.5 \\
\hline$\Sigma$ Endosulfan & $<4.62$ & 4.1 & 76.4 & 15.8 & $<4.62$ & 2899.5 & 254.8 & 296.7 & $<4.62$ & $<4.62$ & $<4.62$ & $<4.62$ & 15.5 \\
\hline$\alpha-\mathrm{HCH}$ & 35.6 & $<4.62$ & $<4.62$ & 12.0 & 12.0 & 541.6 & 41.8 & 5.4 & 3.9 & 50.2 & $<4.62$ & 14.9 & $<4.62$ \\
\hline$\beta-\mathrm{HCH}$ & 17.6 & $<4.62$ & 23.5 & 11.8 & $<4.62$ & 1284.4 & 47.1 & 47.6 & $<4.62$ & $<4.62$ & $<4.62$ & 120.4 & 33.1 \\
\hline$\gamma-\mathrm{HCH}$ & $<4.62$ & $<4.62$ & $<4.62$ & 52.6 & $<4.62$ & 901.2 & $<4.62$ & $<4.62$ & $<4.62$ & 67.7 & $<4.62$ & 33.3 & $<4.62$ \\
\hline$\delta-\mathrm{HCH}$ & $<4.62$ & $<4.62$ & $<4.62$ & 63.3 & $<4.62$ & 1651.5 & 14.3 & $<4.62$ & $<4.62$ & 35.8 & $<4.62$ & 72.2 & $<4.62$ \\
\hline$\Sigma \mathrm{HCH}$ & 53.2 & $<4.62$ & 23.5 & 139.7 & 12.0 & 4378.7 & 103.2 & 53.0 & 3.9 & 153.6 & $<4.62$ & 240.8 & 33.1 \\
\hline Aldrin & $<4.62$ & $<4.62$ & $<4.62$ & 5.5 & $<4.62$ & 274.2 & $<4.62$ & 29.5 & $<4.62$ & 3.9 & $<4.62$ & $<4.62$ & $<4.62$ \\
\hline Dieldrin & $<4.62$ & $<4.62$ & $<4.62$ & $<4.62$ & $<4.62$ & 803.2 & 54.9 & 116.1 & $<4.62$ & $<4.62$ & $<4.62$ & $<4.62$ & $<4.62$ \\
\hline ¿Aldrin & $<4.62$ & $<4.62$ & $<4.62$ & 5.5 & $<4.62$ & 1077.3 & 54.9 & 145.6 & $<4.62$ & 3.9 & $<4.62$ & $<4.62$ & $<4.62$ \\
\hline Endrin & $<4.62$ & $<4.62$ & $<4.62$ & $<4.62$ & $<4.62$ & 588.3 & 2.6 & 88.5 & $<4.62$ & $<4.62$ & $<4.62$ & $<4.62$ & $<4.62$ \\
\hline Endrin aldehido & $<4.62$ & $<4.62$ & 41.1 & 32.4 & $<4.62$ & 407.3 & $<4.62$ & 93.0 & $<4.62$ & $<4.62$ & $<4.62$ & 2.4 & $<4.62$ \\
\hline Endrin cetona & $<4.62$ & $<4.62$ & $<4.62$ & 13.3 & $<4.62$ & 937.6 & 8.8 & 108.6 & $<4.62$ & 1267.4 & $<4.62$ & 1359.2 & $<4.62$ \\
\hline$\Sigma$ Endrin & $<4.62$ & $<4.62$ & 41.1 & 45.7 & $<4.62$ & 1933.3 & 11.4 & 290.0 & $<4.62$ & 1267.4 & $<4.62$ & 1361.7 & $<4.62$ \\
\hline Heptacloro & 39.8 & 7.1 & 83.1 & 98.1 & 40.6 & 1683.6 & 53.0 & 244.3 & 6.4 & 103.6 & $<4.62$ & 233.9 & $<4.62$ \\
\hline $\begin{array}{l}\text { Epoxido de } \\
\text { Heptacloro }\end{array}$ & $<4.62$ & $<4.62$ & $<4.62$ & $<4.62$ & $<4.62$ & 401.8 & $<4.62$ & $<4.62$ & $<4.62$ & $<4.62$ & $<4.62$ & $<4.62$ & $<4.62$ \\
\hline$\Sigma$ Heptacloros & 39.8 & 7.1 & 83.1 & 98.1 & 40.6 & 2085.4 & 53.0 & 244.5 & 6.4 & 103.6 & 0.0 & 233.9 & $<4.62$ \\
\hline trans-Clordano & $<4.62$ & $<4.62$ & $<4.62$ & $<4.62$ & $<4.62$ & 610.0 & 14.1 & 20.7 & $<4.62$ & $<4.62$ & $<4.62$ & $<4.62$ & $<4.62$ \\
\hline cis-Clordano & $<4.62$ & $<4.62$ & $<4.62$ & $<4.62$ & $<4.62$ & 459.2 & 37.2 & 95.7 & $<4.62$ & $<4.62$ & $<4.62$ & $<4.62$ & $<4.62$ \\
\hline$\Sigma$ Clordanos & $<4.62$ & $<4.62$ & $<4.62$ & $<4.62$ & $<4.62$ & 1069.2 & 51.3 & 116.4 & $<4.62$ & $<4.62$ & $<4.62$ & $<4.62$ & $<4.62$ \\
\hline Metoxicloro & 35.5 & 62.2 & 329.1 & 174.7 & 136.8 & 6708.0 & 248.7 & 1018.3 & 116.3 & 373.1 & 0.0 & 1200.6 & $<4.62$ \\
\hline
\end{tabular}

como la genética, la edad, el género, el estado reproductivo, la regulación endocrina e incluso los ritmos circadianos y épocas climáticas, el estado nutricional y de salud de los organismos, la temperatura o la presencia en el medio de metales o biotoxinas (Roberts et al. 1988, Alves-Amaral et al. 2010). Por ello, la evaluación de la AChE como biomarcador específico para la exposición a plaguicidas OP debe complementarse con otros biomarcadores de exposición que puedan dar más información sobre los riesgos que representa los plaguicidas OP. 


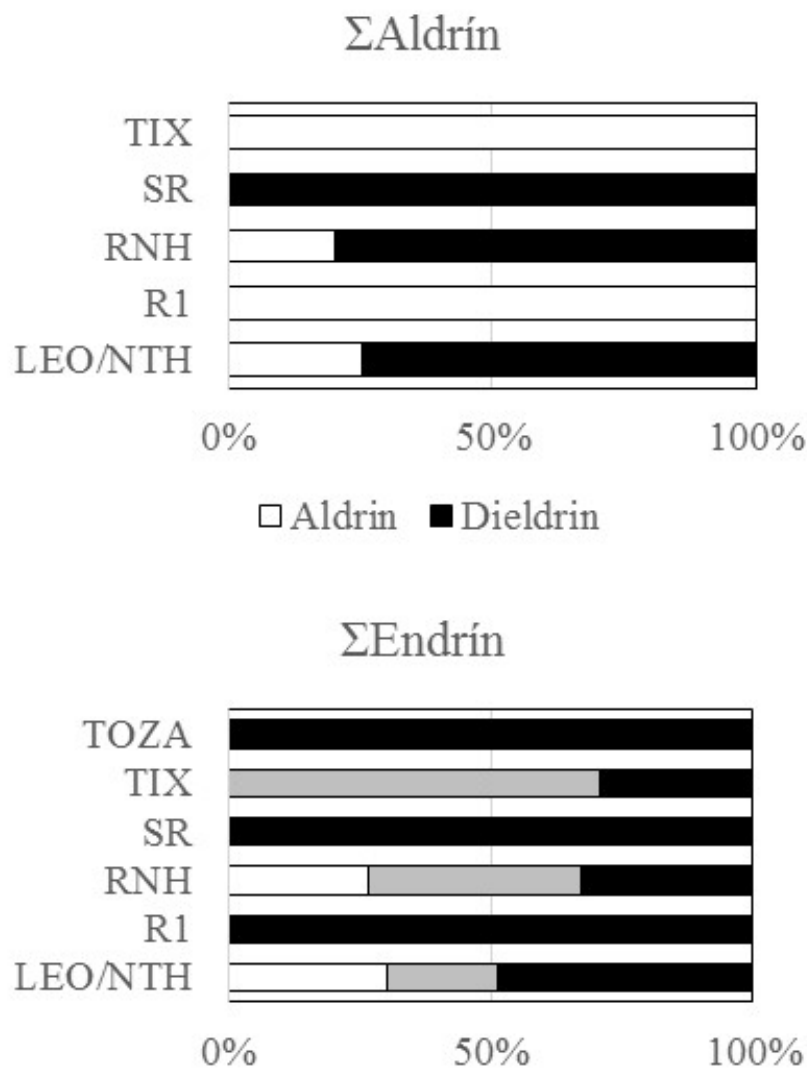

$\square$ Endrin $\square$ Endrin aldehido $\mathbf{\square}$ Endrin Cetona

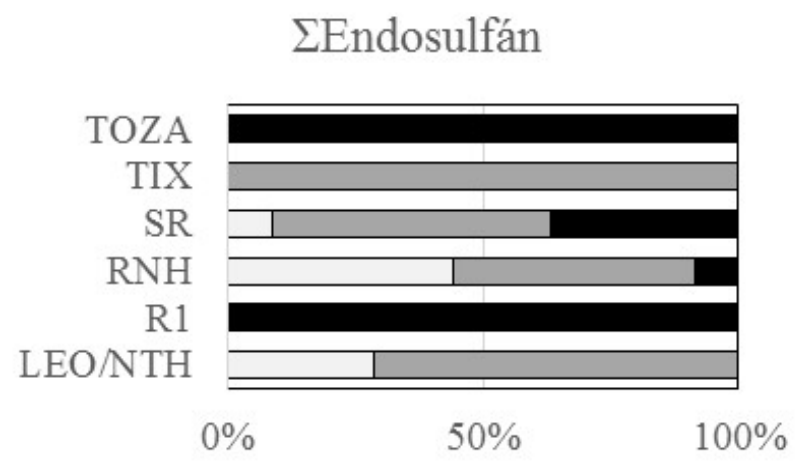

$\square$ Endosulfan I ( $\alpha) \quad \square$ Endosulfan $11(\beta)$

Endosulfan Sulfato

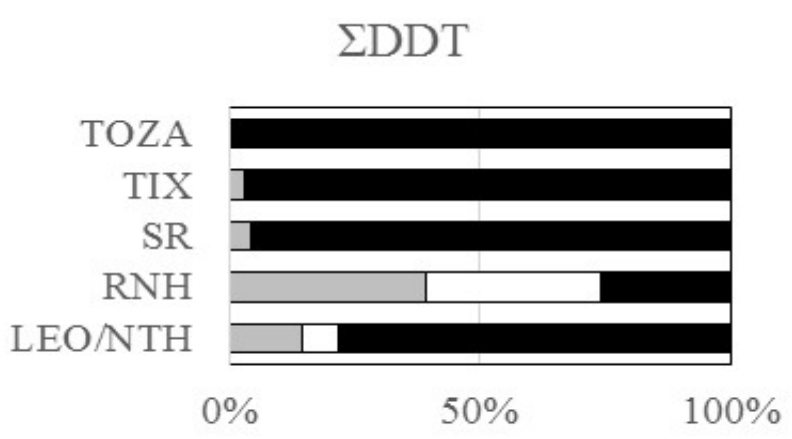

$\square \mathrm{pp}$ ' DDD $\quad \square \mathrm{pp}$ ' DDE $\quad \mathbf{p p p} \mathrm{DDT}$
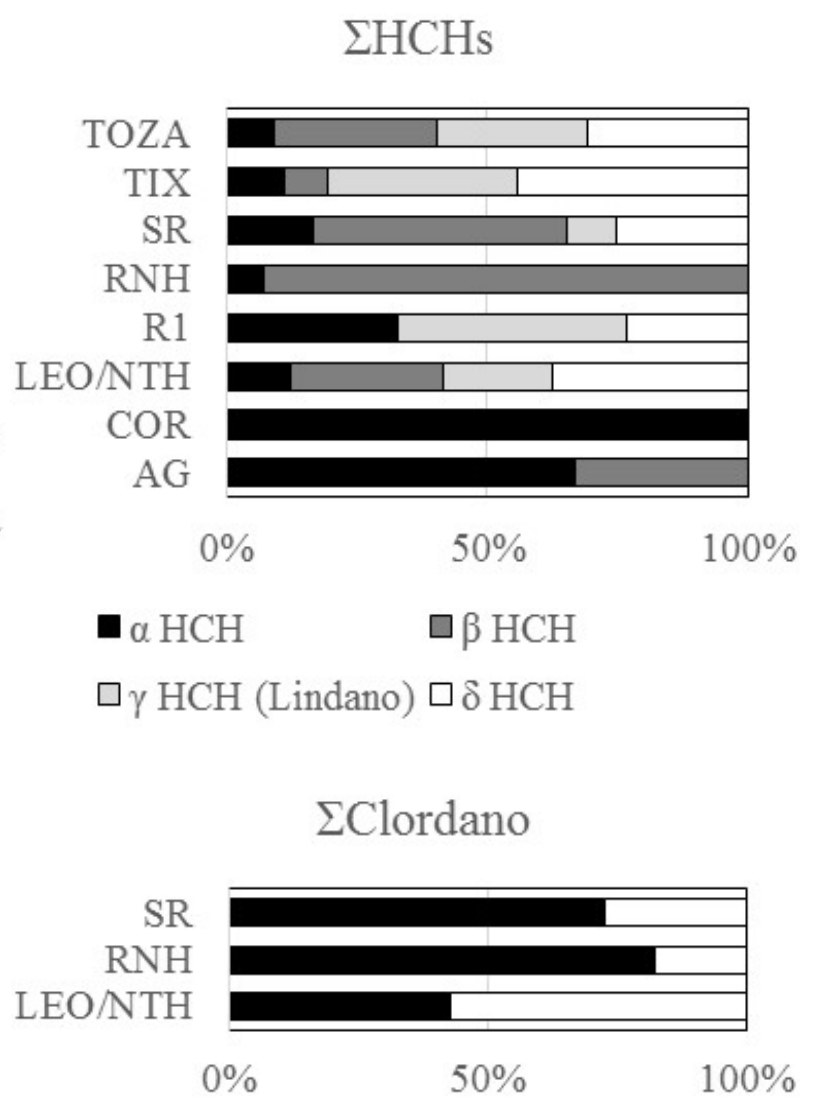

- cis-Clordano $\square$ trans-Clordano

Figura 5. Proporción que ocupan los productos de degradación e isómeros de cada familia de plaguicida por sitio

Compuestos OC en ratones. En este trabajo, las mayores concentraciones de plaguicidas OC se observaron en los ratones de Leona/Nicte-Ha con concentraciones de $\Sigma$ DDT $=5416.7 \mathrm{ng} \cdot \mathrm{g}^{-1}$,

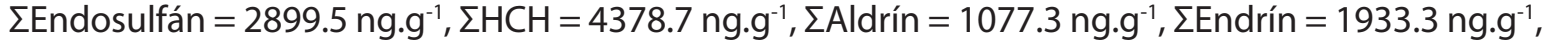
y $\Sigma$ Heptacloro $=2085.4 \mathrm{ng} \cdot \mathrm{g}^{-1}$.

En peces de sitios cercanos a esta área en el sistema Palizada del Este, Díaz-González et al. (2005) reportan concentraciones de $\Sigma$ DDT $=928.8 \mathrm{ng} \cdot \mathrm{g}^{-1}, \Sigma$ Endosulfán $=11.3 \mathrm{ng} \cdot \mathrm{g}^{-1}, \Sigma \mathrm{HCH}=12.56$ ng. $\mathrm{g}^{-1}, \Sigma$ Aldrín $=52.2 \mathrm{ng} \cdot \mathrm{g}^{-1}, \Sigma$ Endrín $=1686.3 \mathrm{ng} \cdot \mathrm{g}^{-1}, \Sigma$ Heptacloro $=44.01 \mathrm{ng} \cdot \mathrm{g}^{-1}$. De manera similar, en ostras y peces de zonas aledañas en Laguna del Este, evaluadas por Carvalho et al. (2009) se detectaron compuestos $\mathrm{OC}$ pero en concentraciones aún menores, del orden de picogramos. 
Esta disminución en las concentraciones de $\mathrm{OC}$ en organismos acuáticos del área puede indicar que los compuestos están poco disponibles ya que se sedimentan junto con las partículas orgánicas a las que se unen por adsorción. En contraste, los organismos terrestres se encuentran en contacto directo con los plaguicidas que se adhieren a la materia orgánica del suelo y puede permanecer por más tiempo.

Para la mayoría de los plaguicidas detectados en el hígado de los ratones, los productos de degradación se encuentran concentrados en mayor proporción indicando mayor exposición de los ratones a dichas sustancias y sugieren que ha transcurrido mucho tiempo desde la última vez que fueron aplicados. Sin embargo, en los sitos La Leona/Nicte Ha, San Román y Tixchel, la

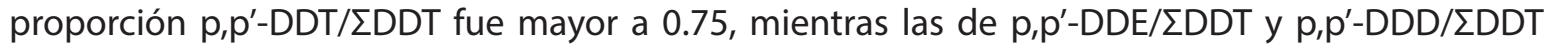
fueron menores a 0.25 , lo que podría sugerir una exposición reciente al p,p'DDT ya que este compuesto ocupa del 60-80 \% del DDT de grado técnico. Sin embargo, la proporción alta de p.p'DDT no necesariamente es signo de una aplicación reciente del plaguicida DDT como tal, ya que el producto de su degradación, el p,p'DDE, tiene mayor volatilidad (hasta ocho veces más que el DDT) y podría estar menos disponible al contacto con los organismos, y por consiguiente se puede bioacumular menos (ATSDR 2002a), por lo que las concentraciones de DDT pueden ser los remanentes de la aplicación intensiva de este compuesto en las campañas de control de vectores en los 90 s.

Por otra parte, desde el 2014 la Secretaría de Agricultura, Ganadería, Desarrollo Rural Pesca y Alimentación (SAGARPA) ha implementado en Campeche el uso del plaguicida organoclorado dicofol en la estrategia para el control del ácaro rojo de las palmas (Raoiella indica Hirst) en los municipios de Carmen y Palizada, al igual que para el control de plagas del limón como el ácaro blanco (Polyphagotar senomuslatus) y el arador o negrilla del fruto. El dicofol de brado técnico puede contener $p, p^{\prime}$-DDT y $p, p^{\prime}$-DDE como impurezas, explicando la presencia de estos compuestos (ATSDR 2002a).

En ratones, se han observado alteraciones en hígado como alargamiento de las células y túbulos centrales a partir de 0.25 a $0.5 \mathrm{mg} / \mathrm{kg} /$ día. El nivel de efecto adverso observable más bajo (LOAEL por sus siglas en inglés) para el DDT en ratones se estima en $0.5 \mathrm{mg} / \mathrm{kg} /$ día para efectos en el desarrollo neuronal, impidiendo la habituación de los organismos (ATSDR 2002a). En este estudio se encontraron concentraciones máximas equivalentes a $\Sigma D D T=2.3 \mathrm{mg} / \mathrm{kg}$ en San Román y $\Sigma$ DDT $=5.4 \mathrm{mg} / \mathrm{kg}$ en La Leona/Nicte-Ha, lo lleva a suponer que los roedores silvestres pueden presentar las alteraciones antes mencionadas en la células hepáticas y en el sistema nervioso.

Otro compuesto que se encontró en proporciones altas en ratones es el $\mathrm{HCH}$. Este suele ser más abundante en su isómero a-HCH en los ambientes acuáticos y en la atmósfera, mientras que el isómero $\beta-\mathrm{HCH}$, el isómero más hidrofóbico y estable, se encuentra mayormente asociado a suelos, tejidos y fluidos animales, similar al isómero $\mathrm{Y}-\mathrm{HCH}$ (Walker 1999). En contraste, se encontró en mayor concentración el isómero a-HCH en el hígado de ratones de los sitios Aguacatal y Los Corralitos, y el $\mathrm{\gamma}-\mathrm{HCH}$ en Rancho R1, lo cual podría indicar una aplicación reciente de $\mathrm{HCH}$ en los sitios antes mencionados, ya que el lindano de grado técnico que se emplea en el control de plagas es una mezcla de varios isómeros del $\mathrm{HCH}$, en donde el a-HCH ocupa del $60-70 \%$ con una vida media de 20 a 50 días, y el $\gamma$ - $\mathrm{HCH}$ (el único con acción insecticida) con una vida media de 20 semanas comprende del 6-10\% (ATSDR 2005). El lindano se emplea como tratamiento para el control de plagas durante la germinación de semillas y en el proceso y el control de ácaros y pulgas en el ganado.

En ratas, el LOAEL en una exposición crónica para el a-HCH a dosis de $0.8 \mathrm{mg} / \mathrm{kg} / \mathrm{día}$ por más de 107 semanas produce efectos en hígado, mientras para el $\beta-\mathrm{HCH}$ es de $0.18 \mathrm{mg} / \mathrm{kg} / \mathrm{día}$ por 13 días para efectos en el hígado. Para el $\gamma-\mathrm{HCH}$, el LOAEL en ratones para inmunotoxicidad es de 6.25 $\mathrm{mg} / \mathrm{kg} /$ día durante cinco semanas (ATSDR 2005). Además, en un estudio realizado por Srivastava y Raizada (2000) se observó que la exposición a dosis de $13.1 \mathrm{mg} / \mathrm{kg} /$ día en la época de apareamiento produce una disminución en la viabilidad de las crías. En este trabajo se encontraron concentraciones máximas de a-HCH equivalentes a $0.54 \mathrm{mg} / \mathrm{kg}$, concentraciones de $\beta-\mathrm{HCH}$ de $1.28 \mathrm{mg} / \mathrm{kg}$ y $\gamma-\mathrm{HCH}$ con $0.9 \mathrm{mg} / \mathrm{kg}$ en La Leona/Nicte-Ha, lo cual sugiere que estos compuestos pueden no estar causando efectos hepáticos o reproductivos negativos en las poblaciones de roedores silvestres. 
El aldrín de grado técnico está conformado en más del $90 \%$ de aldrín, $3.5 \%$ de isodrín y el $6 \%$ restante se reparte entre más de diez compuestos diferentes, y el principal producto de degradación de este compuesto es el dieldrín el cual en suelos tropicales puede desaparecer hasta en un $90 \%$ en un mes, mientras que en zonas templadas puede permanecer hasta cinco años (ATSDR 2002b). Las

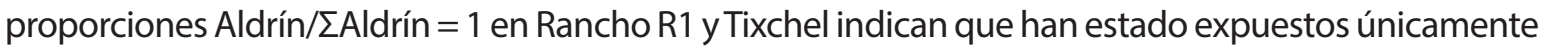
a esa sustancia y no a otros productos de degradación, por lo que se asume la exposición relativamente reciente de este $\mathrm{OC}$, ya que el aldrín se metaboliza rápidamente en el organismo y en el ambiente hacia dieldrin, el cual se bioacumula y biomagnifica (Kloskowski et al. 1981). El principal uso del aldrín fue en el control de termitas, sin embargo, no parece haber alguna fuente local de este OC por lo que podría estar poniéndose en contacto con los organismos mediante deposiciones atmosféricas.

EI LOAEL para la toxicidad en el desarrollo embrionario de ratones, el aldrín se estima en 2 $\mathrm{mg} / \mathrm{kg} / \mathrm{d}$ ía, en tanto que de $2-4 \mathrm{mg} / \mathrm{kg} / \mathrm{día}$ al final de la gestación produce un aumento en el umbral de convulsiones por shock electroconvulsivo cerebral, y una exposición aguda a $25 \mathrm{mg} / \mathrm{kg}$ produce crías con patas palmeadas (ATSDR 2007). En este trabajo se encontró una concentración máxima equivalente a $\Sigma$ Aldrín $=1.07 \mathrm{mg} / \mathrm{kg}$ en el sitio La leona/Nicte-Ha la cual puede no estar causando un efecto observable en los roedores silvestres.

El Heptacloro también se encontró en proporciones de Heptacloro/々Heptacloro > 0.75 en todos los sitios, indicando la exposición relativamente reciente de los organismos a dicho compuesto. Esto debido a que el heptacloro de grado técnico está integrado por más del $70 \%$ de Heptacloro (ATSDR 2007), por lo cual se encuentra acumulado en grandes proporciones en comparación con la proporción Epóxido de heptacloro/乏Heptacloro que apenas alcanza 0.24 en el sitio La Leona/ Nicte-Ha. No se encontró evidencia del uso local de este compuesto por lo que podría encontrarse debido a las deposiciones atmosféricas.

En ratones, el LOAEL en una exposición perinatal aguda en ratas a Heptacloro es de 0.03 $\mathrm{mg} / \mathrm{kg} / \mathrm{día}$ con efectos en el desarrollo de los sistemas nervioso e inmune. En ratas macho, una exposición durante 70 días a $0.65 \mathrm{mg} / \mathrm{kg} /$ día disminuye el número de espermas en el epidídimo e incrementa su reabsorción, mientras en hembras la exposición a $1.8 \mathrm{mg} / \mathrm{kg} / \mathrm{día}$ disminuye la fertilidad y aumenta la resorción de oocitos. También se puede observar lesión hepática, hepatitis, hepatomegalia y necrosis en una exposición aguda de 5-10 mg/kg/día de Heptacloro, en tanto que los daños neurológicos se pueden observar en una exposición aguda a $7 \mathrm{mg} / \mathrm{kg} / \mathrm{día}$ (ATSDR 2007). En este trabajo se detectaron las mayores concentraciones equivalentes a $\Sigma$ Heptacloro $=$ $0.24 \mathrm{mg} / \mathrm{kg}$ en Rancho Nohan y $\Sigma$ Heptacloro $=2.1 \mathrm{mg} / \mathrm{kg}$ para el sitio La Leona/Nicte-Ha, con lo que los sistemas, nervioso, inmune y reproductivo reproductivos pueden verse afectados y podría repercutir en el éxito reproductivo de los roedores silvestres de estos sitios.

Los plaguicidas antes mencionados presentan evidencia de aplicación reciente. Sin embargo, la CICOPLAFEST (2004) categoriza al lindano (HCHs) y al DDT como de uso restringido ya que solamente las instancias de gobierno como la Secretaría de Salud tienen permitido su uso para campañas sanitarias como el control de vectores de enfermedades. De manera similar, el aldrín se encuentra bajo la categoría de uso prohibido, categorías bajo la cual han permanecido estos plaguicidas desde 1991. Por otra parte, el heptacloro no ha sido registrado como plaguicida en México, por lo que su comercio y uso no están permitidos, en tanto que su uso en el área de estudio no está reportado.

Implicaciones para la conservación. Como se ha descrito previamente, los ratones del APFFLT están expuestos a una gran cantidad de plaguicidas derivadas de las actividades agrícolas como los compuestos OP y Carbamatos, así como OC y sus productos de degradación, los cuales se han concentrado y acumulado en el hígado y posiblemente en otros tejidos.

En el presente trabajo no se puede hablar de una evidencia específica de la exposición a plaguicidas OP ya que la inhibición de la actividad de la enzima AChE en músculo y cerebro no fue contundente para la zona de ríos con mayor actividad agrícola y por consiguiente una mayor aplicación de compuestos OP y carbamatos. Se deben tomar en cuenta fuentes adicionales de contaminación las cuales podrían estar influyendo en la inhibición de la AChE como lo son los metales pesados, producto de la extracción de hidrocarburos en la zona costera, en donde se 
observó menor actividad enzimática. Cabe mencionar que los mecanismos que compensan la inhibición de la AChE, como la actividad de la butirilcolinesterasa, puede estar ayudando a los roedores a compensar los efectos de la exposición a plaguicidas anticolinérgicos, evitando los efectos anticolinérgicos como la dificultad de termorregular y la el riesgo a enfermedades neurológicas, lo cual los puede hacer más susceptibles a la depredación (Albert y Loera 2005; Timofeeva et al. 2008; Roegge et al. 2008).

En el caso de los plaguicidas $\mathrm{OC}$, aunque fueron pocos los encontrados en concentraciones por encima del LOAEL, no hay que dejar de lado los posibles efectos adversos a largo plazo. Estos compuestos son altamente bioacumulables debido a que son muy solubles en grasa, lo que les permite unirse a las moléculas lipídicas y permanecer en el tejido graso hasta que se utiliza, momento en el cual los plaguicidas se liberan y producen efectos tóxicos. Como consecuencia se puede producir desde estrés oxidativo, alteraciones en la estructura de las células en órganos internos o pueden fungir como disruptores endócrinos impidiendo la maduración de los gametos hasta la masculinización o feminización de los individuos, además de ser teratogénicos e incluso cancerígenos (Gupta et al. 2009).

La alteración en las respuestas de los ratones ante los cambios ambientales y las interacciones con otros organismos pueden repercutir de manera directa en la composición, estructura y dinámica poblacional al aumentar las tasas de depredación y disminuir la fertilidad cambiando la dinámica de las poblaciones silvestres (Block et al. 1999). Además, los plaguicidas concentrados en los roedores se biomagnifican hacia los niveles superiores de la redes tróficas, con lo cual los depredadores también se ven afectados de diferentes maneras. Uno de los ejemplos más claros se observó en la década de los 60s en las aves rapaces a partir de la disminución del grosor del cascarón de los huevos como consecuencia de la aplicación del DDT (Ratckliffe 1970; Jiménez et al. 2007).

La información obtenida en este trabajo es un panorama general de uno de los eslabones más bajos de la red trófica que puede impactar de manera importante en el nivel superior o a incluso al ecosistema. Es recomendable realizar un monitoreo de los efectos de los plaguicidas sobre los ratones y la fauna que se asocia a ellos en el área de Laguna de Términos mediante el uso de biomarcadores de exposición para determinar los efectos individuales a corto plazo, así como realizar censos, que en conjunto pueden ayudar a comprender los cambios en las estructuras poblacionales a largo plazo.

En este contexto, es importante que las instancias de gobierno encargadas de regular en materia de plaguicidas como son SAGARPA, SEMARNAT y la Secretaría de Salud impulsen la implementación y seguimiento de las estrategias ya existentes de regulación y vigilancia en la distribución y uso de plaguicidas. Dichas acciones deben seguirse particularmente para algunos OC que se encuentran prohibidos o son de uso restringido de acuerdo a las leyes federales como lo son el lindano, aldrín y heptacloro, y que se han encontrado de manera reiterada por diferentes estudios en el área de Laguna de Términos, incluyendo el presente trabajo, y que se encuentran prohibidos o restringidos por las leyes Federales. Además, en el caso de los compuestos anticolinérgicos como los OP y carbamatos que se encuentran permitidos, es crucial que se respeten las dosis y frecuencias recomendadas para el control de plagas en los diferentes cultivos, ya que en muchos casos las aplicaciones se realizan sin tomar en cuenta estos parámetros, afectando a la fauna hacia la cual no van dirigidos dichos compuestos. Lo anterior es fundamental en áreas de importancia biológica como las áreas naturales protegidas como el Área de Protección de Flora y Fauna Laguna de Términos, ya que es uno de los principales reservorios de agua dulce del país y además cuenta con una gran biodiversidad terrestre y acuática que es ampliamente aprovechada por los habitantes de poblados inmersos en dicha zona.

Adicionalmente, es fundamental impulsar el desarrollo de alternativas de producción que no incluyan el uso de plaguicidas sintéticos. Dentro de estas alternativas se encuentra el control biológico de plagas bien diseñado y el uso de compuestos naturales que puedan degradarse con mayor rapidez que a largo plazo producen efectos adversos menores en el ambiente. La agricultura orgánica y el policultivo son opciones que pueden ser benéficas al aumentar la diversidad de especies vegetales y pueden contribuir en la restauración el suelo. 


\section{Agradecimientos}

A CONACyT por el apoyo otorgado a G. Escalona Segura (21467) y en particular por la beca para la realización de los estudios de maestría. A la Comisión Nacional para el Conocimiento y Uso de la Biodiversidad por financiar el proyecto 'Inventario de aves y mamíferos en humedales de Laguna de Términos y Pantanos de Centla en Tabasco y Campeche (LH009)' y a los integrantes de este proyecto por su valioso apoyo en campo. A J. Rendón por facilitar las instalaciones del Laboratorio de Ecotoxicología del Instituto EPOMEX perteneciente a la Universidad Autónoma de Campeche.

\section{Literatura citada}

Albert, L. A., and R. Loera. 2013. Química y Ecotoxicología de los Insecticidas. Pp 178-179, in Golfo de México Contaminación e Impacto Ambiental: Diagnóstico y Tendencias, segunda edición. (Botello A V, J. Rendón-von Osten, G. Gold-Bouchot, and C. Agraz eds.). Universidad Autónoma de Campeche, Universidad Nacional Autónoma de México, Instituto de Ecología. Campeche, México.

Allon, N. L. Raveh, E. Gilat, E. Cohen, J. Crunwald, and Y. Ashani. 1998. Prophylaxis against Soman Inhalation Toxicity in Guinea Pigs by Pretreatment Alone with Human Serum Butyrylcholinesterase. Toxicological Sciences 43:121-128.

Álvarez-Castañeda, S.T., T. Álvarez, and N. González-Rulz. 2015. Guía para la identificación de los mamíferos de México en campo y laboratorio, primera edición. Centro de Investigaciones Biológicas del Noroeste, S. C. Asociación Mexicana de Mastozoología A. C. Ciudad de México, México.

Alves-Amaral, G., M. Pires-Oliveira, A. L. Andrade-Lopes, T. Chiavegatti, and R. Oliveira Godinho. 2010. Gender-related differences in circadian rhythm of rat plasma acetyl- and butyrylcholinesterase: Effects of sex hormone withdrawal. Chemico-Biological Interactions 186:9-15.

Andrade-Herrera, M. 2011. Evaluación del efecto de la contaminación atmosférica en dos especies del género Peromyscus (Rodentia: Muridae) que cohabitan en el Parque Nacional Desierto de los Leones. Universidad Autónoma Metropolitana. Unidad Iztapalapa

Astroff, A. B., And A. D. Young. 1998. The relationship between maternal and foetal effects following maternal organophosphate exposure during gestation in the rat. Toxicology and Industrial Health 14:869-89.

ATSDR. 2002a. Toxicological profile for DDT, DDT, DDE, and DDD. 403.

ATSDR. 2002b. Toxicological profile for aldrin/dieldrin. 303.

ATSDR. 2005. Toxicological profile for alfa-, beta-, gamma- y delta-hexachlorocyclohexane. 325.

ATSDR. 2007. Toxicological Profile for Heptachlor and Heptachlor Epoxide. 158.

Block E, T. Lacher, and R. Kendall. 1993. Effect of the organophosphate pesticide Encounter in laboratory deer mice Peromyscus maniculatus. Environmental Toxicology and Chemistry 12:377-383.

Block E. K., T. E. Lacher, L. W. Brewer, G. P. Cobb, and R. J. Kendall. 1999. Population Responses of Peromyscus Resident in lowa Cornfields Treated with the Organophosphorus Pesticide COUNTER. Ecotoxicology 8:189-200.

Botello, A. V., J. L. Rojas-Galaviz, J. Benítez, and D. Zárate-Lomelí. 1998. Golfo de México, Contaminación e Impacto Ambiental: Diagnóstico y Tendencias. Programa Sectorial De Medio Ambiente 19982005. Gobierno del Estado de Campeche. Secretaria de Ecología. Universidad Autónoma de Campeche, Epomex Serie Científica 5. Campeche, México.

Bouchard, M., G. Carrier, R. C. Brunet, P. Dumas, and N. Noisel. 2006. Biological monitoring of exposure to organophosphorus insecticides in a group of horticultural greenhouse workers. The Annals of Occupational Hygiene 50:505-515

Bourgeon, S., E. H. K. Leat, R. W. Furness, K. Borga, S. A. Hansen, and J. O. Bustnes. 2013. Dietary versus maternal sources of organochlorines in top predator seabird chicks: an experimental approach. Environmental Science and Technology 47:5963-70. 
Bradford, M. M. 1976. A Rapid and Sensitive Method for the Quantitation of Microgram Quantities of Protein Utilizing the Principle of Protein-Dye Binding. Analitical Biochemistry 72:248-254.

Campoy, F. J., J. Cabezas-Herrera, and C. J. Vidal. 1992. Interaction of acetylcholinesterase with Lens culinaris agglutinin reveals differences in glycosylation of molecular forms in sarcoplasmic reticulum membrane subfractions. The Journal of Neuroscience 33:568-578.

Carvalho, F. P., J. Villeneuve, C. Cattini, J. Rendon, and J. M. de Oliviera. 2009. Pesticide and PCB residues in the aquatic ecosystems of Laguna de Términos, a protected area of the coast of Campeche, Mexico. Chemosphere 74:988-995.

Castro F., and T. Yoshida. 1971. Degradation of Organochlorine Insecticides in Flooded Soils in the Philippines. Journal of Agriculture and Food Chemistry 19:1168-1170.

Chamucero-Santacoloma, J. C., E. Trujillo-Trujillo, and D. A. Jimenez-Carvajal. 2011. La biodiversidad y el papel de los ingenieros de ecosistemas en su mantenimiento. Momentos de Ciencias 8:8-15.

CICOPLAFEST. 2004. Catálogo de plaguicidas. Comisión Intersecretarial para el Control del Proceso y Uso de Plaguicidas, Fertilizantes y Sustancias Tóxicas. Ciudad de México, México.

CONAGUA. 2007. Regiones Hidrológicas, escala 1:250000. República Mexicana. Ciudad de México, México.

Dell'Omo, G., M. G. Pleskacheva, D. P. Wolfer, H. P. Lopp, and R. F. Shore. 2003. Comparative effects of exposure to an organophosphate pesticide on locomotor activity of laboratory mice and five species of wild rodents. Bulletin of Environmental Contamination and Toxicology 70:138-45.

Depledge, M. H., ANd M. C. Fossı. 1994. The role of biomarkers in environmental assessment (2). Invertebrates Ecotoxicology 3:161-172

Díaz-González, G., A. V. Botello, and G. Ponce-Velez. 2005. Plaguicidas Organoclorados en Pastos y Peces de los Sistemas Candelaria-Panlau y Palizada del Este Laguna de Términos, Campeche. Pp. 207-223, in Golfo de México. Contaminación e Impacto Ambiental: Diagnóstico y Tendencias (Botello A. V., J. von Osten, G. Gold-Bouchot, and C. Agraz-Hernández, eds.). Universidad Autónoma de Campeche, Universidad Nacional Autónoma de México, Instituto Nacional de Ecología. Campeche, México.

Ellman, G. L., K. D. Courtney, V. J. Andres, and R. M. Featherstone. 1961. A new and rapid colorimetric determination of acetylcholinesterase activity. Biochemical Pharmacology 7:88-95.

EPA. 1996. SW-846 Test Method 3540C: Soxhlet Extraction. Journal of Chemical Information and Modeling.

EPA. 2011. Pesticides Industry Sales and Usage. 2006 and 2007 Market Estimates. Biological and Economic Analysis Division, Office of Pesticide Programs, Office of Chemical Safety and Pollution Prevention.

Fernie, K. J., AND R. J. Letcher. 2010. Historical contaminants, flame retardants, and halogenated phenolic compounds in peregrine falcon (Falco peregrinus) nestlings in the Canadian Great Lakes Basin. Environmental Science and Technology 44:3520-3526.

Fildes, K., J. K. Szabo, L. Astheimer, M. Hooper, and W. A. Butterman. 2009. Plasma cholinesterase characteristics in native australian birds: significance for monitoring avian species for pesticide exposure. Emu: Austral Ornithology 109:41-47.

Fulton, M. H., AND P. B. Key. 2001. Acetylcholinesterase inhibition in estuarine fish and invertebrates as an indicator of organophosphorus insecticide exposure and effects. Environmental Toxicology and Chemistry 20:37-45.

Ghadiri, H., C. W. Rose, and D. W. Connell. 1995. Degradation of Organochiorine pesticides in soils under controlled environment and outdoor conditions. Journal of Environmental Management 43:141-151.

González-Castillo, M., C. N. Aguilar, and R. Rodríguez-Herrera. 2012. Control de insectos-plaga en la agricultura utilizando hongos entomopatogenos: retos y perspectivas. Revista Científica la Universidad Autónoma de Coahuila 4:42-45.

Gupta, R. K. , S. Meachum, I. Hernández-ochoa, J. Peretz, H. Yao, and J. A. Flaws. 2009. Methoxychlor inhibits growth of antral follicles by altering cell cycle regulators. Toxicology and Applied Pharmacology 240:1-7. 
Hemingway, J., and H. Ranson. 2000. Insecticide resistance in insect vectors of human disease. Annual Review of Entomology 45:371-391.

IUCN. 2015. The IUCN Red List of Threatened Species. Version 2015-4. <http://www.iucnredlist.org>. Accessed 19 Nov 2015

Jiménez, B., B. Merio, E. Abad, J. Rivera, and K. Olie. 2007. Evaluation of organochlorine compounds (PCDDs, PCDFs, PCBs and DDTs) in two raptor species inhabiting a mediterranean island in Spain. Environmental Science and Pollution Research 2:61-68.

Jones, G., And E. C. Teeling. 2006. The evolution of echolocation in bats. Trends in Ecology and Evolution 21:149-56.

Karpuzcu, M. E., D. L. Sedlak, and W.T. Stringfellow. 2013. Biotransformation of chlorpyrifos in riparian wetlands in agricultural watersheds: Implications for wetland management. Journal of Hazardous Material 244-245:111-120.

Kloskowski R., I. Scheunert, AND W. Klein y F Korte. 1981. Laboratory screening of distribution, conversion and mineralization of chemicals in the soil-plant-system and comparison to outdoor experimental data. Chemosphere 10:1089-1100.

Lartiges S. B., And P. P. Garrigues. 1995. Degradation Kinetics of Organophosphorus and Organonitrogen Pesticides in Defferent Waters under various Environmental Conditions. Environmental Science and Technology 29:1246-1254.

LiU, B., L. L. McConnell, AND A. TorRents. 2001. Hydrolysis of chlorpyrifos in natural waters of the Chesapeake Bay. Chemosphere 44:1315-1323.

Mackay, D., J. P. Giesy, and K. R. Solomon. 2014. Fate in the environment and long-range atmospheric transport of the organophosphorus insecticide, chlorpyrifos and its oxon. Reviews of Environmental Contamination and Toxicology 231:35-76.

Mehranı, H. 2004. Protective effect of polyurethane immobilized human butyrylcholinesterase against parathion inhalation in rat. Environmental Toxicology and Pharmacology 16:179-185.

Mitsch, W. J., AND J. G. Gosselink. 2000. The value of wetlands: importance of scale and landscape setting. Ecological Economics 35:25-33

Orona-Castro, F. 2008. Tecnología de producción de arroz. Inofap-SAGARPA.

Payne, J. R., A. Mathieu, W. Melvin, and L. L. Fancey. 1996. Acetylcholinesterase, and Old Biomarker with a New Future? Field Trails in Assosiation with Two Urban Rivers and a Paper Mill in Nowfoundland. Marine Pollution Bulletin 32:225-231.

Poissant, L., C. Beauvais, P. Lafrance, and C. Deblois. 2008. Pesticides in fluvial wetlands catchments under intensive agricultural activities. Science of the Total Environment 404:182-195.

Quinn, G. P., AND M. J. KeOUGH. 2007. Experimental design and data analysis for biologists, sexta edición. Cambridge University Press. Cambrige, United Kingdom.

Ramírez-Elías, M. A., A. V. Córdova-Quiroz, J. G. Cerón-Bretón, R. M. Cerón-Bretón, J. Rendón-von Osten, and J. H. CoRtés-Simón. 2016. Dichloro-diphenyl-trichloroethane (DDT) and endosulfan in sediments of Sabancuy Lagoon, Campeche, Mexico. Open Journal of Ecology 6:22-31.

Ratcliffe, D. A. 1970. Changes Attributable to Pesticides in Egg Breakage Frequency and Eggshell Thickness in Some British Birds. Journal of Applied Ecology 7:67-115.

Raveh, L., E. Grauer, J. Grunwald, E. Cohen, and Y. Ashani. 1997. The Stoichiometry of Protection against Soman and VX Toxicity in Monkeys Pretreated with Human Butyrylcholinesterase. Toxicology and Applied Pharmacology 145:43-53.

REID, F. 2009. A Field Guide to the Mammals of Central America and Southeast Mexico, segunda edición. Oxford University Press. Oxford, United Kindom.

Reyes-Montero, J. A. 2014. Tecnología para la producción de mango en alta densidad de plantación. Colegio de postgraduados. Campeche, México. 
Roberts, D. K., N. J. Silvey, And E. M. Bailey. 1988. Brain Acetylcholinesterase Activity Recovery Following Acute Methyl Parathion Intoxication in Two Ferai Rodent Species: Comparison to Laboratory Rodents. Bulletin of Environmental Contaminations and Toxicology 41:26-35.

Roegge, C. S., O. A. Timofeeva, And F. J. Seidler. 2008. Developmental diazinon neurotoxicity in rats: later effects on emotional response. Brain Research Bulletin 75:166-72.

Salame Méndez, A., F. Méndez, G. Aguirre, and H. Serrano. 2008. Disrupción endocrina de la diferenciación sexual. ContactoS 70:43-49.

SAGARPA. 2014. Norma Oficial Mexicana NOM-033-SAG/ZOO-2014. Métodos para dar muerte a los animales domésticos y silvestres. Diario Oficial de la Federación, Segunda Sección. Ciudad de México, México.

SEMARNAT. 2010. Norma Oficial Mexicana NOM-059-SEMARNAT-2010. Protección ambientalEspecies nativas de México de flora y fauna silvestres - Categorías de riesgo y especificaciones para su inclusión, exclusión o cambio - Lista de especies en riesgo. Diario Oficial de la Federación, Segunda Sección. Ciudad de México, México.

SNedekER, S. M. 2001. Pesticides and Breast Cancer Risk: A Review ofDDT, DDE, and Dieldrin. Environmental Health Perspectives 109:35-47.

Srivastava, M. K., and R. B. Raizada. 2000. A limited three-generation reproduction study on hexachlorocyclohexane $(\mathrm{HCH})$ in rats. Food and Chemical Toxicology 38:195-201.

SSA. 2001. Programa de Acción: Enfermedades Transmitidas por Vector. Secretaría de Salud. Ciudad de México, México.

StoRy, P., AND M. Cox. 2001. Review of the effects of organophosphorus and carbamate insecticides on vertebrates. Are there implications for locust management in Australia? Wildlife Research 28:179-193.

Timofeeva, O. A., C. S. Roegge, F. J. Seidler, T. A. Slotkin, and E. D. Levin. 2008. Persistent cognitive alterations in rats after early postnatal exposure to low doses of the organophosphate pesticide, diazinon. Neurotoxicol Teratol 30:38-45.

Tucuch Cauich, F. M., A. Palacios Pérez, R. Ku Naal, and C. Guzmán Estrada. 2005 Manejo del cultivo de mango en el estado de Campeche. 45.

VAn der Oost, R., J. Beyer, ANd N. P. E. Vermeulen. 2003. Fish bioaccumulation and biomarkers in environmental risk assessment: A review. Environmental Toxicology and Pharmacology 13:57-149

Villalobos, G. J. 2015. Conservación y manejo del Área de Protección de Flora y Fauna "Laguna de Términos" (1994-2015). Pp. 1-20, in Aspectos socioambientales de la región de la laguna de Términos, primera edición. Campeche. Universidad Autónoma de Campeche. Campeche, México.

WALKER, K. 1999. Factors influencing the distribution of lindane and other hexachlorocyclohexanes in the environment. Enviromnental Science and Technology. 33:4373-4378.

Walker, C. H., R. M. Sibly, S. P. Hopkin, and D. B. Peakall. 2012. Principles of Ecotoxicology, cuarta edición, CRC Press. Boca de Raton, U.S.A.

Willis, G. H, J. F. Parr, S. Smith, and B. R. Carroll. 1972. Volatilization of dieldrin from fallow soil as affected by different soil water regimes. Journal of Environmental Quality 1:193-196.

Submited: June 20, 2016

Reviewed: July 3, 2016

Accepted: September 14, 2016

Associated editor: Lia Mendez 